\title{
AS FACES DA CIDADE: MIGRAÇÕES HISTÓRICAS NO MUNICÍPIO DE SANTOS/SP
}

\author{
THE FACES OF THE CITY: HISTORICAL MIGRATIONS IN \\ SANTOS/SÃO PAULO/BRAZIL
}

Wellington Teixeira Lisboa ${ }^{1}$

\begin{abstract}
RESUMO: Apresenta-se um breve panorama sobre os fluxos de migrações internacionais alocados no município litorâneo de Santos, no estado de São Paulo, na transição do século 19 ao século 20 . Com este propósito, identificam-se as principais correntes migratórias formadas no contexto da economia cafeeira paulista, período histórico no bojo do qual esta cidade protagonizou metamorfoses estruturantes na sua composição territorial e populacional. A sistematização e o exame da historiografia e de fontes institucionais primárias cooperam com a produção dessa narrativa a respeito do tecido multicultural que, desde os oitocentos, demarcou as faces urbanísticas e demográficas de Santos.
\end{abstract}

PALAVRAS-CHAVE: Economia do café. Imigração. Santos. Território

ABSTRACT: This study presents a brief overview about the flows of international migrations located in Santos, a coastal city in the state of São Paulo, Brazil, in the transition from the 19th to the 20th century. Therefore, the study identifies the main migratory flows formed in the context of the São Paulo' coffee economy. It was in this historical period that this city made important metamorphoses in its territorial and population composition. The systematization and examination of historiography and primary institutional sources cooperate with the production of this narrative about the multicultural composition that demarcated the urban and demographic identities of Santos since the nineteenth century.

KEYWORD: Coffee economy. Immigration. Santos. Territory

\footnotetext{
* Pesquisa decorrente da tese apresentada no Programa de Pós-graduação em Sociologia do Instituto de Filosofia e Ciências Humanas da Universidade Estadual de Campinas (Unicamp), sob a orientação da Profa. Dra. Rosana Baeninger e ao abrigo do Observatório das Migrações em São Paulo, sem financiamento.

1 Professor Adjunto no Departamento Acadêmico de Linguagem e Comunicação da Universidade Tecnológica Federal do Paraná (UTFPR). Doutor em Sociologia pela Universidade Estadual de Campinas (Unicamp). wtlisboa@yahoo.com.br
} 
Introdução

A transição do século 19 para o século 20 representou um período histórico de notoriedade para o entendimento da configuração urbana e demográfica de uma cidade central no mapa geopolítico paulista e brasileiro, o município litorâneo de Santos. Por sua estrutura portuária, ao ritmo do escoamento das volumosas sacas de café e das transações comerciais intercontinentais de importação e exportação, somaram-se as regulares correntes migratórias d'além-mar, que viriam a compor os territórios do interior do estado de São Paulo e da sua capital, dinamizados pela economia agroexportadora cafeeira.

Com efeito, esse movimento portuário amparou o processo de povoamento, urbanização e modernização da larga extensão territorial estadual e, numa escala mais abrangente, respaldou o próprio desenvolvimento econômico brasileiro até pouco antes da Segunda Guerra Mundial. Prado Júnior (1989) chegou a afirmar que São Paulo e Santos formaram um único circuito geoeconômico sistêmico, cujo sustentáculo se retroalimentava e lançava as bases indispensáveis para a tardia dinâmica de industrialização nacional.

Mas não fora a sua condição particular como cais de passagem ou rota de riquezas e de mão de obra livre que imputara à essa cidade portuária o destaque que lhe é (ou deveria ser) conferido na história brasileira das migrações internacionais. Tal como afirma Cano (2007), ao complexo econômico cafeeiro integraram-se nódulos dinamizadores de um conjunto de atividades estruturais sem as quais seria impensável o êxito desse ciclo. O complexo cafeeiro em Santos, como particularizou Gonçalves (2006), na esteira do pensamento daquele autor, caracterizou-se como um dos polos corresponsáveis pela logística e vitalidade desse tipo de economia agroexportadora e, por esse mesmo motivo, afiançou, localmente, o cenário de oportunidades para a fixação de imigrantes de distintas nacionalidades nesse litoral paulista (Mapa 1). 
Mapa 1 - Localização de Santos no litoral de São Paulo

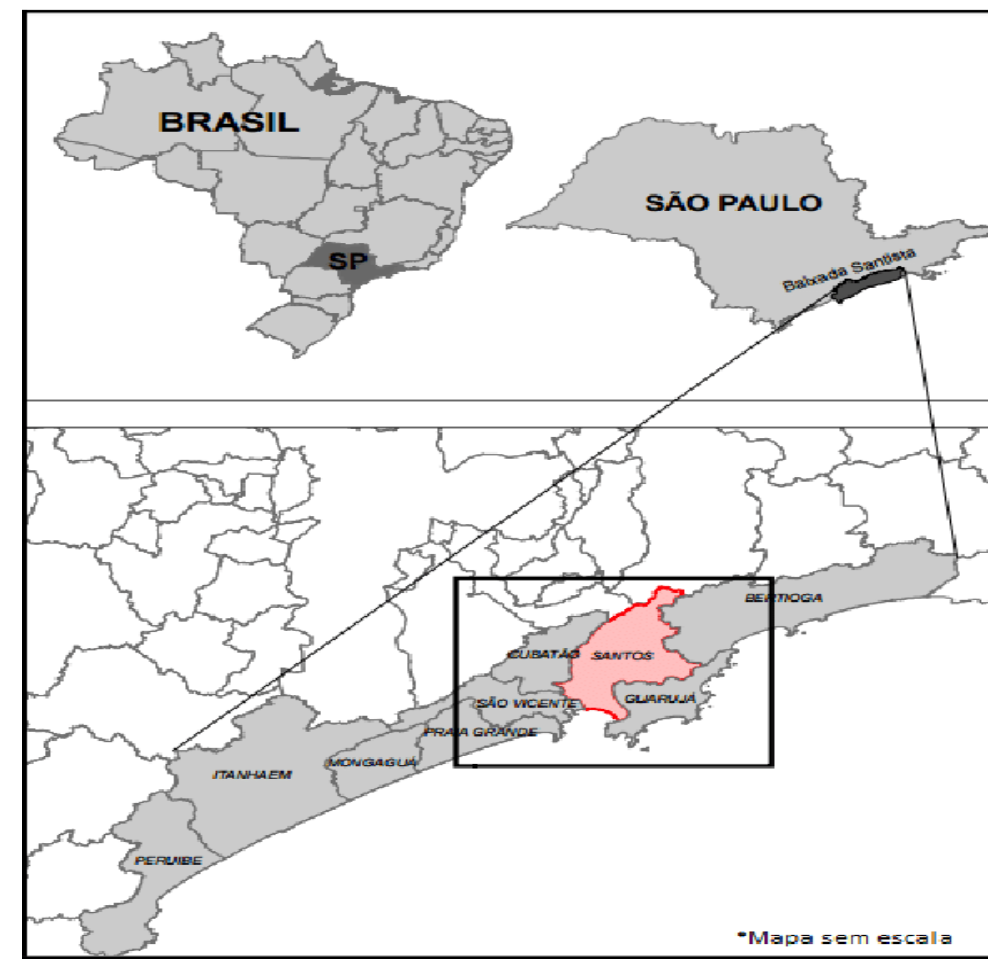

Fonte: Zoneamento Ecológico-Econômico do Setor da Baixada Santista. Secretaria de Estrutura e Meio Ambiente do Estado de São Paulo, Site institucional, 2019.

Isso quer dizer que o protagonismo santista na história das migrações no Brasil não deve se restringir à sua condição como estrutura portuária central para o trânsito massivo de imigrantes com destinos além-planalto. Como território multicultural, Santos fez-se e refez-se com a presença de imigrantes em seu solo. O presente estudo, fruto de uma investigação em nível de doutorado, tem como objetivo apresentar um panorama dos principais fluxos migratórios internacionais destinados a Santos no contexto da economia cafeeira paulista. Dada a diversidade de nacionalidades dos imigrantes que residiram nessa cidade portuária nas últimas décadas dos oitocentos e nas primeiras dos novecentos, o cenário aqui exposto evidencia apenas um plano geral sobre o processo de constituição do território santista de migrações internacionais, não tendo a expectativa e as condições requeridas para 
aprofundar certas particularidades e alterações temporais do perfil de cada nacionalidade de imigrantes, tampouco suas dinâmicas próprias de territorialização, por grupo, em torno das experiências de trabalho, dos vínculos afetivo-comunitários e culturais, das estratégias individuais e coletivas de sobrevivência, entre outros pontos.

Tendo em vista este foco mais generalista, recorre-se à sistematização e análise da historiografia sobre o assunto, debruçando-se sobre os estudos que ilustram e problematizam o compasso das transformações oitocentistas das paisagens urbanas e demográficas de Santos, com atenção aos contributos teóricos e empíricos ofertados por Andrade (1989), Lanna (1996), Gonçalves (2006), em diálogo direto com as pesquisas que esclarecem o período da expansão da economia cafeeira paulista (PRADO JÚNIOR, 1989; FAUSTO, 1999; CANO, 2007) e suas implicações no enredamento transoceânico de correntes de imigrantes que rumaram aos territórios da então próspera província de São Paulo (PETRONE, 1999; BASSANEZI, 1996, 1998; BAENINGER, 2012), entre eles, o território santista (PEREIRA, 1980; HANDA, 1987; FRUTUOSO, 1990; CAMARGO, 2006; CÁNOVAS, 2010; LISBOA, 2015).

Igualmente cooperam com o desenvolvimento deste panorama sobre a presença de imigrantes em Santos na transição entre os séculos 19 e 20 o levantamento e o exame de fontes primárias, de posse de organizações governamentais e empresariais santistas (SANTOS, 1914; A TRIBUNA, 1914, 1929, 1982) e outras de atuação federal (FIBGE, 1872, 1900, 1920), como os recenseamentos da população residente no Brasil e particularmente em Santos nas décadas de 1870 a 1900 e no dealbar deste último século.

\section{São Paulo e Santos: 'cidades casadas'}

O período histórico da considerada 'grande imigração' no Brasil, desencadeada a partir da segunda metade do século 19, situou a cidade de Santos como um dos territórios protagonistas da dinâmica das migrações internacionais no país. Essa representatividade vinculou-se ao processo de 
formação econômica e social de algumas regiões brasileiras, particularmente da região paulista, sustentada pela agricultura do café, que dependeu do Porto de Santos para o escoamento do produto e para a recepção de mercadorias e de mão de obra para as lavouras do interior, entre outras atividades (FAUSTO, 1977; CANO, 2007).

A vasta historiografia em torno da economia cafeeira destaca como um dos eixos temáticos centrais nesse panorama oitocentista, que se adensou no fim e na virada daquele século, a chegada de imigrantes europeus e asiáticos nos territórios paulistas e as relações de trabalho estabelecidas nas fazendas e em toda a logística de exportação do café. Substancialmente, os estudos evidenciam a importância dos fluxos migratórios não apenas na direta viabilidade operacional da economia cafeeira, mas, de modo articulado, na própria configuração dos comércios, dos transportes, na urbanização das cidades, na introdução de costumes morais e, em geral, na composição dos aspectos demográficos e socioculturais da população paulista em formação (HOLLOWAY, 1984; BASSANEZI, 1996).

Assim, à pujante produção agroexportadora do café, identificada por Cano (2007), entre outros intelectuais brasileiros, como força motriz das dinâmicas econômicas e sociais que ganharam corpo na segunda metade do século 19, acoplaram-se inúmeras atividades corresponsáveis pelo redesenho dos cenários rurais e urbanos da promissora região paulista, inclusive do seu litoral, cujo tecido populacional passara a congregar firmes traços de origem estrangeira. Entre as iniciativas articuladas, Cano (2007) menciona a produção de alimentos e matéria-prima; as atividades bancárias e as transações de importação/exportação; o comércio interno; os sistemas ferroviário, marítimo e de transporte urbano; os empreendimentos ligados à infraestrutura, como a expansão dos armazéns santistas e das instalações portuárias; os sistemas de comunicações aquém e além-planalto e os investimentos do poder público no complexo cafeeiro integrado.

Petrone (1990) explica que, no contexto do fortalecimento econômico que culminou na instauração do regime republicano de governo, o avanço dos 
cafezais demandou grande volume de mão de obra, principalmente porque a alta taxa de mortalidade decorrente das doenças e das más condições de trabalho e a supressão oficial do tráfico negreiro, que prenunciava o fim das políticas escravistas no Brasil, gradualmente, forçaram a revisão ideológica do perfil de trabalhador para as fazendas do interior de São Paulo, onde se localizavam os solos mais adequados a essa monocultura. De fato, com o declínio da produção nas regiões cafeeiras do Vale do Paraíba e do Litoral Norte, como Ubatuba e São Sebastião, e com a procedente marcha dos cafezais para o Oeste de São Paulo (PRADO JÚNIOR, 1989), grande parte da comercialização do mais importante produto do império brasileiro, o café, centralizou-se no porto santista, que paulatinamente se transformou em cais de recepção de imigrantes. Foi com a ampliação e o incremento das lavouras cafeeiras do interior paulista e a necessidade de aparelhamento do porto para a exportação dos grãos de café que Santos, bem como outros conglomerados populacionais dessa região provincial, viu suas composições urbanísticas e demográficas se remodelarem no desenrolar do século 19.

Não por acaso, em 1822, decorridos cerca de três séculos de sua fundação sob o poderio da Coroa Portuguesa, a vila de Santos possuía 4.781 habitantes (ÁLVARO, 1919), passando a 5.863, entre população livre (3.266) e escrava (2.597), catorze anos depois (MÜLLER, 1923). Em 1854, quando já lhe tinha sido outorgado o título de cidade $^{2}$ e o volume da exportação cafeeira começava a suplantar o da negociação internacional do açúcar, Santos registrou 7.885 habitantes, sendo 710 estrangeiros (SANTOS, 1914). Note-se que apenas os municípios de Iguape, no auge da cultura do arroz, Limeira, dinamizada pelos engenhos de açúcar e posteriormente pelas lavouras cafeeiras, e São Paulo ultrapassavam essa quantidade de estrangeiros em seus territórios (BASSANEZI, 1998).

\footnotetext{
${ }^{2}$ A vila de Santos foi elevada à categoria de cidade em 26 de janeiro de 1839, pela Lei $\mathrm{n}^{\circ} 122$, sancionada por Venâncio José de Lisboa, então presidente da Província de São Paulo. Este ato administrativo denotava a crescente importância econômica e política daquele núcleo portuário. À exceção de Iguape, localizado no Vale do Ribeira, todos os demais núcleos do litoral da Província de São Paulo continuavam, àquela data, sob a denominação administrativa de vila (ANDRADE, 1989).
} 
É importante reconhecer, nesse panorama histórico, que a instalação da linha férrea da São Paulo Railway Company, em 1867, possibilitou o escoamento da robusta produção cafeeira do interior ao litoral paulista, viabilizando o fortalecimento do comércio interno, a importação de bens de consumo, de matérias-primas, equipamentos, produtos manufaturados e, evidentemente, a exportação dos grãos de café a países dos continentes europeu, americano e asiático. De acordo com Fausto (1999), a ferrovia SantosJundiaí, sob a responsabilidade daquela companhia inglesa, compôs a infraestrutura necessária para a logística estratégica de negociação do café, uma vez que garantia o transporte vigoroso, ágil e regular, do 'ouro verde' que, então, afiançara o desenvolvimento de São Paulo até as primeiras décadas do século 20 .

Como 'cidades casadas', tal como as considerou Prado Júnior (1989), São Paulo e Santos formaram um único circuito geográfico sistêmico, no qual a cidade praiana operava como ponto nevrálgico de articulação mercadológica com o exterior, ao passo que, para a capital paulista, convergiam fluxos de riquezas que abasteciam o interior e, por sua vez, retroalimentavam essa relação de interdependência planalto/litoral. Foi nesse contexto de centralidade binômica junto à capital e à sua extensão territorial que, em Santos, a entrada de imigrantes ganhou volume no último quartel oitocentista, com o desembarque de milhares de pessoas que se destinavam às promissoras cidades do Oeste, muito embora porções significativas de estrangeiros tenham se fixado nessa faixa litorânea.

\section{Além do cais: Santos, território de imigrantes}

As migrações internacionais em Santos, a partir da segunda metade do século 19 e com ênfase nas duas últimas décadas, devem ser compreendidas no âmbito do movimento da 'grande imigração' no Brasil, em particular na região de São Paulo, maior centro brasileiro de plantação e exportação da monocultura do café. No último quartel oitocentista, o comércio importador e exportador 
que, geograficamente, se expandia o mais próximo possível do cais santista já sinalizava a vitalidade das modificações urbanas e populacionais naquela cidade ainda simplória e por muito tempo com ares de vila colonial (ANDRADE, 1989).

Não por acaso, foram construídos numerosos escritórios de café, para ensacamento, torrefação e venda do produto; casas importadoras; estabelecimentos bancários estrangeiros; muitos cortiços (BLUME, 1999); armazéns de secos e molhados, de armarinhos e de fazendas; tipografias, tão indispensáveis à impressão de anúncios, panfletos, revistas e jornais da cidade operária que começava a sentir, na base, sua ebulição econômica e social. Também passaram a constituir esse cenário urbano as representações consulares, como a da Itália, da Bélgica, da Áustria, da França, da Hungria, da Holanda, da Alemanha, da Inglaterra, dos Estados Unidos, do Chile, do Uruguai, entre outras, denotando a visibilidade do cais santista como entreposto da crescente movimentação do café, de produtos e matérias-primas e também como espaço de trânsito de pessoas na América. Nesse quadro, que aponta para o incremento da divisão social e territorial do trabalho e para o robustecimento da diversidade da vida urbana, registra-se o vaivém cotidiano das gentes: os engraxates, os marinheiros, as prostitutas, as 'damas da sociedade', as lavadeiras, ambulantes, proletários, comerciantes, os comissários (PEREIRA, 1980), os corretores do café, os passantes anônimos, os estrangeiros recémchegados.

Para efeitos de representação numérica, resgatamos o levantamento censitário imperial de 1872, que registrou 9.191 habitantes em Santos, sendo 168 estrangeiros, dos quais 61 africanos na condição de escravos, 42 africanos livres, 62 portugueses e três italianos (FIBGE, 1872). Na somatória, esses dados expõem uma pequena diferença frente ao número apresentado pelo censo produzido, naquele mesmo ano, pelo próprio governo municipal, em que constam 9.151 moradores (SANTOS, 1914). Contudo, no que concerne especificamente aos estrangeiros, as incompatibilidades estatísticas são notórias e relevantes: enquanto o documento da administração imperial certificou a 
quantidade de menos de duzentos estrangeiros residindo no território santista, a comissão censitária local detectou 1.577 indivíduos de nacionalidades diversas, listadas na Tabela 1, a seguir. Essa divergência, convém frisar, é reconhecida e claramente criticada naquele relatório municipal, no qual incisivas suspeições são desferidas quanto à credibilidade dos métodos adotados na contagem populacional que abrangeu todo o território do Império e, inclusive, quanto aos interesses que a salvaguardaram.

Tabela 1 - Distribuição dos estrangeiros em Santos por nacionalidade, em 1872

\begin{tabular}{lr} 
Nacionalidade & $\mathrm{n}$ \\
\hline \hline Portugueses & 931 \\
\hline \hline Africanos & 255 \\
\hline \hline Alemães & 137 \\
\hline Franceses & 75 \\
\hline \hline Espanhóis & 55 \\
\hline \hline Norte-americanos & 35 \\
\hline \hline Ingleses & 31 \\
\hline \hline Suíços & 18 \\
\hline \hline Italianos & 18 \\
\hline \hline Outras nacionalidades & 22 \\
\hline \hline Total & $\mathbf{1 . 5 7 7}$ \\
\hline \hline
\end{tabular}

Fonte: Recenseamento da Cidade e Município de Santos, 31/12/1913. Prefeitura de Santos, 1914.

Representando em torno de $17 \%$ da população residente no município em 1872 e tendo como volume mais expressivo o grupo nacional dos portugueses, como revela a Tabela 1, esses estrangeiros não integravam o movimento que, de fato, reuniria os traços estruturais do que, nas décadas posteriores, estabelecer-se-ia, em escala massiva, como a 'grande imigração' no Brasil. De todo modo, intercruzando as estatísticas sistematizadas pelo censo municipal santista e o levantamento populacional sob a responsabilidade do governo imperial, ambos datados de 1872, emergem indicadores significativos e que merecem a atenção: a) do total (29.622) de estrangeiros distribuídos em toda a província de São Paulo, 5,3\% localizavam-se em Santos, computando

\footnotetext{
${ }^{3}$ Compreendem os seguintes estrangeiros: quatro suecos, três holandeses, três austríacos, três chineses, dois dinamarqueses, dois argentinos, dois 'orientais', um húngaro, um belga, um russo.
} 
1.577 pessoas; b) excluindo-se os africanos nas condições de cativos e libertos, o contingente de estrangeiros em toda a região provincial não ultrapassava, como elucidado (Tabela 1), o montante equivalente a $2 \%$ dos seus habitantes; Santos, por sua vez, contava com $14,4 \%$ de estrangeiros em sua composição populacional, também excluindo dessa contagem os sujeitos provenientes do continente africano; c) por fim, 13,8\% dos portugueses identificados em toda a extensão da geografia paulista residiam nesse município litorâneo.

Até as duas últimas décadas do século 19, os cerca de mil portugueses residentes em Santos constituíam, de fato, o mais expressivo coletivo de imigrantes nessa cidade, tendo participado de importantes metamorfoses estruturais que seguiam em ritmo vigoroso nas adjacências do cais portuário. Além desses, tal como indica a Tabela 1, a historiografia registra ainda um contingente de alemães não superior a 150 pessoas, entre os quais constam os empregados no trabalho de interligação físico-geográfica entre Santos e Cubatão, povoado localizado no sopé da Serra do Mar, ponto estratégico de circulação de mercadorias entre o porto e o planalto. A presença germânica na manutenção de obras viárias, inclusive, já havia sido notada pelo missionário metodista norte-americano Daniel Kidder, quando de sua estada nesse litoral, em 1839 (KIDDER, 1972).

Não obstante esses fluxos pontuais de trabalhadores, Camargo (2006) assegura que havia alemães que desempenhavam atividades no comércio, os que eram proprietários de grandes firmas familiares, de importação e de navegação (como a Theodor Wille \& Cia, a Otto Helme \& Cia., a Vocherodut \& Cia., a Zerrenner \& Bulow, a C. Budich), os que respondiam como cônsules, mesários, mordomos, e também os farmacêuticos e os médicos que atuavam na Santa Casa da Misericórdia. Poucos deles, portadores privilegiados de aristocrática afluência social, faziam “[...] parte do clã mais influente dentro da Cidade e cuja notoriedade, [sic] ultrapassa de muito em prestígios os limites de Santos e da Província" (CAMARGO, 2006: s/p.).

É preciso considerar, contudo, que assim como os alemães viventes em Santos na década de 1870 ainda não integravam o fenômeno da 'grande 
imigração' no Brasil, não se caracterizando, portanto, um fluxo massivo sistemático e regular, os franceses, espanhóis e ingleses também eram poucos em termos numéricos e detinham características peculiares nas suas trajetórias de imigração, com base nas quais se revelaria contraproducente compreendê-los sob um prisma similar àquele especializado nos deslocamentos populacionais sucedidos após a década de 1880. Carvalho (1982), na primeira versão da coleção temática intitulada Os Imigrantes - conjunto de reportagens publicadas em edição comemorativa do jornal impresso A Tribuna -, explica que os poucos franceses residentes em Santos em 1871, contabilizados em 75 indivíduos (Tabela 1), eram proprietários ou mesmo funcionários de estabelecimentos de capital francês em operação na praça comercial santista, a exemplo de uma filial da Chargeurs Réunis, especializada em agenciamento de navios, a Auguste Leuba \& Cia., focada nas atividades comerciais de navegação, importação e exportação, entre outras.

Quanto aos espanhóis, que, em 1872, somavam 55 habitantes (Tabela 1), há registros de alguns estabelecimentos comerciais, pertencentes a imigrantes dessa nacionalidade, em funcionamento desde 1852. Mas só nas derradeiras décadas oitocentistas, esses estrangeiros de origem ibérica ultrapassariam uma centena de pessoas em Santos (CÁNOVAS, 2010). Como negociantes e empresários, operários em obras particulares, escritores, aventureiros ou autoridades consulares, os ingleses, por sua vez, também se enquadravam nesses deslocamentos pontuais de europeus com diminuta representatividade numérica na costa litorânea paulista, como evidencia o recenseamento santista anteriormente citado, muito embora seja improvável conjecturar que a relevância desses sujeitos na estrutura física e econômica de Santos tenha sido igualmente débil, para não dizer das modificações que provocaram nos hábitos socioculturais e estilos de vida sedimentados nos cotidianos dessa urbe.

Agentes importantes da cidade portuária em expansão, um grupo de ingleses atuou na instalação da linha férrea da São Paulo Railway, popularmente conhecida como a 'Inglesinha', nas obras de infraestrutura urbana 
da Companhia City, na Western Telegraph Company, nas atividades de navegação da Royal Mail Steam Packet e em outras empresas de origem britânica. Como vem sendo enfatizado neste estudo e tal como se verifica na Tabela 2, a seguir, somente em meados de 1880 esta cidade registrou considerável aumento de sua população, com a chegada massiva da mão de obra europeia para prover as demandas geradas pelo complexo cafeeiro integrado (CANO, 2007) que se estendia aquém e além-montanhas da Serra do Mar, consolidando um organismo econômico sistêmico (PRADO JÚNIOR, 1989) que desembocava no cais santista.

Tabela 2 - População em Santos (1772-1886)

\begin{tabular}{cccccc}
$\begin{array}{c}\text { Ano do } \\
\text { Censo }\end{array}$ & $\begin{array}{c}\text { População } \\
\text { livre }\end{array}$ & $\begin{array}{c}\text { População } \\
\text { escrava }\end{array}$ & $\begin{array}{c}\% \\
\text { População } \\
\text { escrava }\end{array}$ & $\begin{array}{c}\text { População } \\
\text { total }\end{array}$ & $\begin{array}{c}\text { Taxa de } \\
\text { crescimento } \\
(\% \text { a.a })\end{array}$ \\
\hline 1772 & 2.081 & - & - & 2.081 & - \\
\hline 1814 & 2.993 & 2.135 & 41,6 & 5.128 & 0,87 \\
\hline 1816 & 2.827 & 2.053 & 42,0 & 4.880 & $-2,81$ \\
\hline 1822 & 2.696 & 2085 & 43,6 & 4.781 & $-0,79$ \\
\hline 1828 & 2.728 & 2.348 & 45,6 & 5.146 & 0,30 \\
\hline 1854 & 4.666 & 3.189 & 40,5 & 7.855 & 2,09 \\
\hline 1872 & 7.585 & 1.606 & 17,5 & 9.151 & 2,74 \\
\hline 1886 & - & - & - & 15.605 & 5,29 \\
\hline
\end{tabular}

Fonte: Adaptada do Recenseamento da Cidade e Município de Santos, 31/12/1913. Prefeitura de Santos, 1914.

Algumas constatações são particularmente relevantes no que concernem ao recenseamento da população santista nos anos arrolados nesta tabela. A primeira refere-se à densidade de habitantes nesse litoral por todo o período colonial e ao longo do Segundo Reinado, que chegou a pouco mais de sete mil indivíduos apenas na década de 1850, confirmando as evidências já sistematizadas pela historiografia em torno do processo de formação urbana e do povoamento de Santos, que ganha corpo somente com o ciclo do café (PEREIRA, 1980; SANTOS; LICHT, 1986; ANDRADE, 1989; LANNA, 1996; GONÇALVES, 2006).

A segunda chama a atenção à evidência de que, no longo período secular de 1772 a 1872, a variação populacional no município aumentou pouco mais de quatro vezes, também considerando, nesse universo, a presença 
contextualizada do contingente de escravos africanos, que sempre representou quase a metade dos indivíduos no cômputo geral dessa população. É igualmente elucidativo notar que no período correspondente à passagem de sete décadas, ou seja, de 1814 a 1886, o volume populacional mais que triplicou, no quadro das transformações mercantis e urbanas sucedidas num ritmo relativamente moderado. Por fim, foi a partir dos últimos anos oitocentistas que esse quadro demográfico, de fato, protagonizou uma alteração substancial, ultrapassando 15 mil habitantes em 1886, às vésperas da oficialização das medidas abolicionistas em curso e do dealbar do regime republicano.

É oportuno ainda referir que as transformações políticas, econômicas e populacionais desencadeadas em muitos países da Europa contribuíram para o direcionamento desses fluxos transatlânticos ao Brasil, em particular ao estado de São Paulo. No assim denominado 'velho mundo', o contínuo processo de industrialização e os esforços para o desenvolvimento do capitalismo foram também assegurados pelo controle do crescimento demográfico, com italianos, portugueses, espanhóis, alemães incentivados a rumarem às terras férteis do 'novo mundo'. Como explica Fausto (1999), essas populações, em especial as do sul da Europa, fugiram da generalizada situação de pobreza e das dificuldades de sobrevivência e de manutenção dos modos de vida, alterados pela desigual distribuição fundiária e pela revolução agrícola em curso, com a mecanização e inserção de novas culturas facilitadas pelas inovações industriais. A economia de subsistência dos camponeses, nesse panorama, viuse submetida a um vigoroso processo de mercantilização, pautado pela apropriação institucionalizada, da parte do governo e da Igreja, e pela concentração de terras entre uma burguesia nascente, que ainda se beneficiou do surgimento de novas tecnologias.

Como corolário, restava aos agricultores, despojados de suas terras e de seus modos de vida tradicionais, a competição pelas escassas oportunidades de trabalho junto aos grandes latifúndios produtivos, oferecendo sua mão de obra em troca de módico dinheiro para a sobrevivência familiar. Além desses, pesaram também, nos locais de origem, os fatores atinentes aos conflitos e 
guerras coloniais, às obrigatoriedades impostas por regimes militares e também pela Igreja, sendo a vida eclesiástica, para os jovens, uma das poucas saídas estratégicas com base na qual se poderia colaborar com o sustento das famílias, sobretudo nas aldeias e cidades pequenas daquele continente. Como válvula de escape, os territórios da América passaram a ser representados no imaginário social europeu como o sonho do Eldorado a ser conquistado, isto é, a representação mítica da fortuna e da possibilidade de enriquecimento rápido.

Sobre essa dinâmica processada entre os trabalhos da imaginação e a materialidade do cotidiano dos potenciais imigrantes, Leite (1993), investigador que se debruça sobre a temática dos fluxos oitocentistas da emigração portuguesa ao Brasil, sublinha que a propaganda desempenhou papel central na cristalização de um imaginário que estimulou a adoção de novos planos a se concretizarem além-mar. As práticas imaginativas coletivamente partilhadas reuniam, por certo, expressivas ambivalências psicológicas e existenciais despoletadas num panorama de contingências sociais, políticas, econômicas, tecnológicas historicamente situadas e datadas. Os instrumentos governamentais ou não oficiais de comunicação pareciam, pois, adentrar um universo social de representações imaginárias no bojo do qual se acionava uma dimensão prospectiva em torno de projetos de vida a serem realizados em distintas paragens geográficas ou, em outros termos, em mundos imaginados diferenciados, num presente próximo ou relativamente longínquo.

Ocorre que, na 'terra das promessas', para onde se deslocaram homens, mulheres, crianças, jovens, famílias, a empreitada das migrações internacionais tornara-se, enfim, um projeto viável e real, facilitado pelo desenvolvimento dos transportes ferroviários e, principalmente, dos transportes marítimos. Com efeito, o avanço tecnológico no campo dos transportes e das comunicações representou a base elementar para a expansão capitalista ao longo do século 19 e 20, possibilitando a instituição de circuitos espaciais estruturados de comercialização de matérias-primas, equipamentos e produtos e a intensa movimentação de pessoas entre países e continentes (HOBSBAWM, 2009). Nessa linha de entendimento, o contínuo aperfeiçoamento científico e 
tecnológico imprimiu novas escalas temporais e espaciais aos deslocamentos maciços de mercadorias, de pessoas e ao transporte de informações, costumes e ideias, fato que acrescentou densos matizes à história econômica e social contemporânea.

A gradual substituição dos veleiros por grandes embarcações movidas a vapor representou um desses acontecimentos históricos de proporções vastas e incalculáveis. Entregues durante semanas consecutivas à força do mar e dos ventos, os veleiros eram capazes de transportar, além de produtos e outros materiais, não mais do que duzentas pessoas, sujeitas a toda sorte de infortúnio, inclusive de rápido adoecimento e morte, e prolongamentos fatigantes do tempo até então planejado para a viagem. Leite (1991) enfatiza que as dimensões concernentes à velocidade, à segurança na execução da rota traçada e ao aumento do volume e do peso suportado pelos navios a vapor, além dos aspectos referentes às condições de higiene, à qualidade dos serviços e acomodações, garantiram o protagonismo desse tipo de embarcação a partir de meados do século 19, não obstante as altas taxas cobradas. Por essa via marítima, tão indispensável ao movimento massivo de europeus a distintos territórios da América, hordas de imigrantes foram impulsionadas a dar seqüência a suas narrativas biográficas no Brasil, portando consigo a expectativa de auferir lucros suficientes para a garantia de melhores condições de vida aos que partiram e aos que permaneceram na terra natal.

Dos oitocentos aos novecentos, a virada de séculos, que registrou aumento determinante no perfil populacional de Santos, foi caracterizada pela regularidade e consolidação do fenômeno da imigração massiva para o interior cafeeiro e para o seu eixo portuário de comercialização e exportação, justificando a subida acelerada do volume de populações nessa cidade para 50.389 pessoas em 1900, conforme dados do censo demográfico federal relativo àquele ano (FIBGE, 1900). Assim, se considerarmos que, em catorze anos, de 1872 a 1886 (Tabela 2), esse município apresentou o primeiro saldo positivo de mais de seis mil habitantes, cálculo deveras revelador para a conjuntura histórica da época, o que se verificou nos catorze anos subsequentes foi um 
avanço quantitativo que atingiu a proporção de mais de $200 \%$ no seu cômputo geral de habitantes, que se diversificava.

Nesse panorama, o Estado de São Paulo passou de 837.354 habitantes em 1872 para 1.384.753, em 1886, e 2.279.608, em 1900. Só o município de São Paulo, com quem Santos compunha, estruturalmente, o sistema das 'cidades casadas' (PRADO JÚNIOR, 1989) na economia agroexportadora, saltou de pouco mais de 30 mil para quase 240 mil habitantes no mesmo período mencionado, isto é, de 1872 a 1900 (FIBGE, 1900). Em todo o território nacional, o volume de entrada de imigrantes registrou 1.646.949 pessoas, no período compreendido entre os anos 1880-1899, sendo que a taxa geométrica de crescimento anual de ingresso de europeus chegou a 9\% entre 1872 e 1899 (BAENINGER, 2012).

Frutuoso (1990), com relação ao povoamento de Santos, afirma que, em 1891, quando a cidade dispunha do aparelhamento de parte de sua infraestrutura urbana básica, embora ainda bastante precária, viviam no município 23.055 portugueses, isto é, 20 mil a mais do que se registrou em 1872 (Tabela 1). Permanecendo como o maior grupo de imigrantes por décadas sucessivas, os portugueses eram provenientes dos territórios da Ilha da Madeira, dos Açores e das regiões ao norte daquele país europeu, como dos distritos do Porto e de Braga, mas foram especialmente os madeirenses que, inicialmente, desbravaram as encostas dos morros santistas inabitados e que, a pouco menos de duzentos metros acima do nível do mar, demarcavam os horizontes espaciais até então conhecidos da cidade. É significativo que, no calendário oficial de feriados e datas comemorativas de Santos, constem atualmente leis municipais como a de $n^{\circ} 230$, sancionada em 1987, que institui a Semana Luso-Brasileira, anualmente comemorada entre os dias 20 e 27 de abril; a de $n^{\circ} 1.790$, promulgada em 1999, que celebra o Dia de Portugal, de Camões e das Comunidades Portuguesas, comemorado todos os anos no dia 10 de junho; a lei $\mathrm{n}^{\mathrm{o}}$ 2.566, de 2008, referente ao Dia da Lusofonia, festejado no dia 05 de outubro. 
Quanto aos espanhóis, expressiva corrente migratória que também teve como destino essa cidade litorânea paulista, o saldo quantitativo evoluiu de um quadro de 55 indivíduos (Tabela 1) a 8.491, nesse mesmo recorte temporal, de 1872 a 1891. Os imigrantes espanhóis que se fixaram em Santos eram oriundos, quase que exclusivamente, de uma única região daquela Península, a Galícia, onde se situam as quatro províncias nortenhas de onde partiram muitos dos seus habitantes ao Brasil e a outros territórios da América: La Coruña, Orense, Pontevedra e Lugo (MARTÍNEZ, 1999; PORTA, 2007). Em 1895, mesmo ano da fundação do Centro Português de Santos, posteriormente denominado Real Centro Português, o coletivo de espanhóis fundou o Centro Español, conhecido inicialmente como Casino Español. Segundo Lisboa (2017), essas iniciativas de caráter associativista compuseram um rico conjunto de conteúdos históricos que narraram e ainda expressam as marcas territoriais das migrações internacionais em Santos.

A terceira nacionalidade que se fazia notar no agitado cotidiano santista daquela virada de séculos, muito embora, em termos numéricos, não se apresentasse tão volumosa quanto as relacionadas à Portugal e à Espanha, dizia respeito à população italiana. Apesar da escassa literatura sobre a distribuição espacial desses imigrantes no litoral paulista, Firveda (1990) e Ramos (1990), em seus trabalhos monográficos de natureza bastante sumária, afirmam que muitos deles também passaram a residir em Santos, ainda que o grande fluxo desses imigrantes, como mão de obra tida como prioritária pelas políticas de subvenção para a imigração (PETRONE, 1990), dirigia-se diretamente às fazendas cafeeiras do interior de São Paulo. Para auxiliar os recém-chegados e promover a integração entre o grupo nacional que permanecia nesse litoral, que certamente computava muito mais do que os dezoito indivíduos contabilizados em 1872 (Tabela 1), sem se saber ao certo a sua quantidade nos anos posteriores, fundou-se, em Santos, a Società Italiana di Beneficenza, em 1897, também instalada no cerne do conglomerado que se metamorfoseava nas cercanias do porto. 
Com efeito, a exemplo dos portugueses e espanhóis, os italianos assumiram atividades centrais naquele contexto de profundas transformações urbanas, sobretudo no ramo do comércio e das transações portuárias. Não por acaso, anualmente, no dia 2 de julho, é comemorado o Dia da Coletividade Italiana, data oficializada pela lei municipal 1.787, promulgada em 1999, com o objetivo de "homenagear a imensa e laboriosa colônia italiana residente em Santos e que muito contribuiu e contribui para o desenvolvimento de nossa cidade", nas palavras do vereador propositor da lei (LASCANE, 2015: s/p.). Essas três nacionalidades representaram as que tiveram os mais expressivos fluxos de suas populações destinadas a Santos na virada do século do café e que, portanto, constituíram objeto de estudo da ainda diminuta historiografia acerca desse período do povoamento do município santista.

Sobretudo os provenientes da Península Ibérica, os imigrantes desempenharam uma variedade de atividades indispensáveis naquele cenário urbano em reconstituição, como pedreiros, carpinteiros, marceneiros, serralheiros, ferreiros, estivadores, marmoristas, artífices especializados nos serviços com cimento e gesso, em tacos de madeira para piso e outros artefatos que passariam a compor a estética dos domicílios das classes média e alta, se nesses moldes, levando em consideração a conjuntura socioeconômica da época, for possível tal classificação. Além da responsabilidade por esses ofícios, identificados por Frutuoso (1990, 2008), Matos (1995), Martínez (1999), Pereira (2008), entre outros autores, os imigrantes portugueses e espanhóis, mas não exclusivamente, como também os italianos e os sírios, foram centrais na dinâmica de introdução e difusão de um conjunto de ocupações típicas a cidades em processo de modernização, atuando, por exemplo, como ourives, sapateiros e alfaiates, figuras de destaque na nova divisão social do trabalho comumente requisitadas pela elite cafeeira e pela emergente camada burguesa. Os membros dessas classes sociais passaram a adotar e a ostentar novos costumes e estilos de vida, tal como similarmente ocorrera nas cidades europeias que se industrializaram e se tornaram, não sem perda de vidas humanas e com impactos de toda ordem, importantes centros de 
produção econômica e de propagação de tendências artísticas e culturais, nos idos do século 19 (HOBSBAWM, 2009).

Para além de colaborarem com a introdução de novos hábitos e produtos consumidos pela burguesia nascente, muitos portugueses e espanhóis, que representavam os coletivos populacionais mais numerosos, ainda desbravaram, nas suas territorialidades laborais, o ramo do comércio varejista e da prestação de serviços, adquirindo considerável fortuna, se bem que os italianos, terceiro maior contingente, também se posicionaram como pequenos empreendedores na cidade que crescia e se modificava, comprimida entre a baía oceânica, o canal portuário e as elevações montanhosas (Mapa 2), além de se destacarem na construção de esculturas e no traçado de novos padrões para a arquitetura urbana local, como constatou Serrano (1995), em seu levantamento sobre os aspectos arquitetônicos emergentes nas edificações santistas do ciclo do café. Lamberg (1986: 320), contudo, após sua curta estada em Santos, assim percebeu a composição étnica do mercado local: "A parte mais importante do commercio está nas mãos dos portuguezes, allemães e inglezes”.

Mapa 2- Planta da Cidade de Santos e seus Arrabaldes, 1903

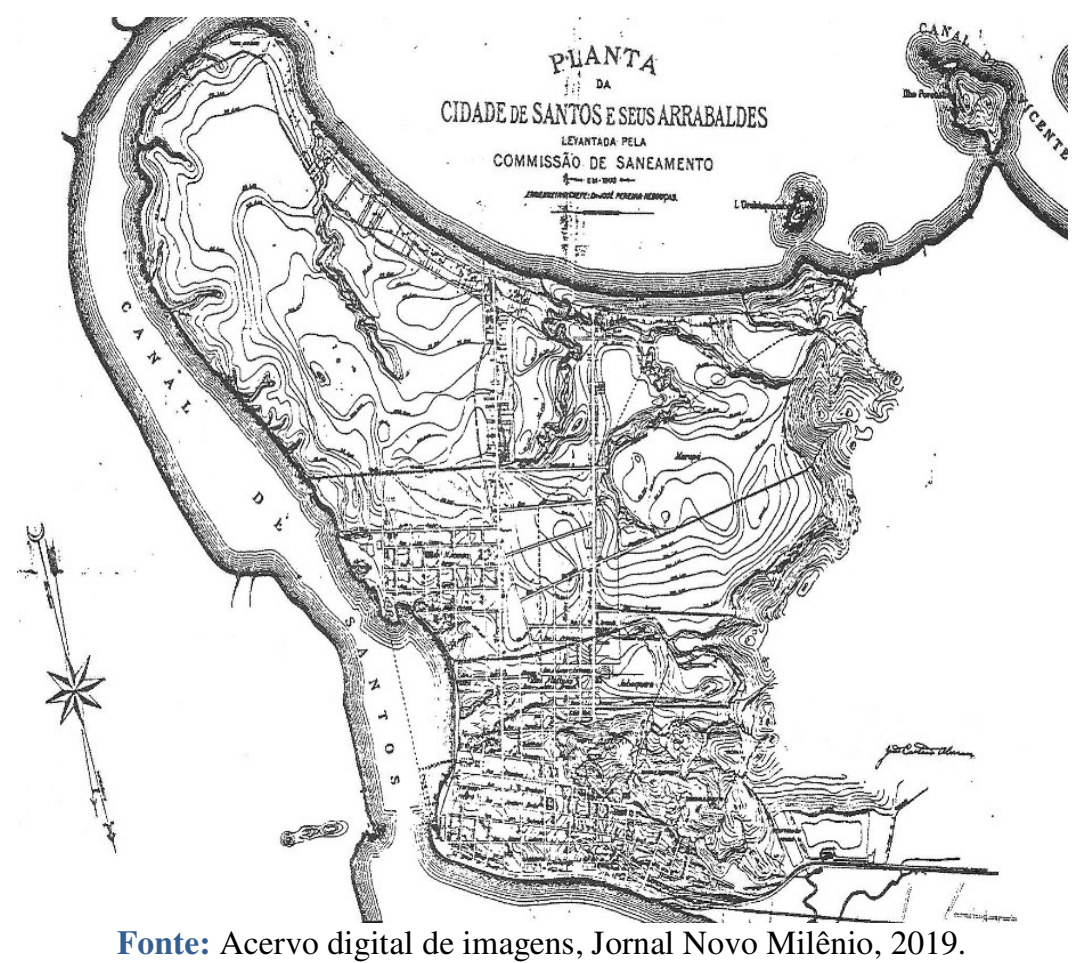

Tempos Históricos • Vol. 24 • n.2 (2020), p. 166-198 
Havia muitos imigrantes europeus que, não podendo arcar com os custos alusivos à instalação da própria oficina ou comércio, se dedicavam a trabalhos itinerantes, de oferta de serviços domésticos de manutenção e consertos gerais, assim descritos por Matos (1995: 74): “[...] jardineiros, capinadores de quintal, empalhadores, lavadores e enceradores de casa, desentupidores, limpadores de calhas, podadores de árvores, exterminadores de formigas, rachadores de lenha". Vale pontuar que, naquele contexto oitocentista finissecular, pesava também o fato de a sociedade brasileira classificar o trabalho manual como inferior e indigno, até mesmo ultrajante, reverberando os estigmas do não tão distante passado colonial e escravista que abriram espaço para a mão de obra estrangeira.

Esta historiadora, tal como Frutuoso (1990), também chama a atenção ao mercado de trabalho destinado às mulheres imigrantes, responsáveis por uma multiplicidade de atribuições que lhes foram imputadas segundo ordenações ideológicas e papéis de gênero historicamente legitimados nas civilizações ocidentais, ancoradas em profundas raízes patriarcais. A presença feminina fazia-se notória, particularmente, na prestação de serviços de limpeza e de cuidado de casas de famílias, bem como na lida como lavadeiras, engomadoras de roupa dos funcionários do porto e como bordadeiras. Matos (1995) e Frutuoso (1995) acentuam que, além de terem de dar conta dos afazeres rotineiros do lar, muitas portuguesas, espanholas e italianas atuaram no ramo da costura de sacaria, em armazéns de secos e molhados, nas adegas de conhecidos, nas quitandas de frutas e legumes, nas atividades de catação de café e de restolho em galpões e mercados, nos botequins de familiares já instalados na cidade, sempre auferindo parca remuneração pelos serviços prestados, para não dizer das que, entre essas, se prostituíam.

A respeito do mercado de trabalho reservado às mulheres, é preciso citar, ainda, a figura das 'escravas brancas', as 'polacas', que pelas ruas das cercanias do porto, entre a Amador Bueno, a João Pessoa e suas vias contíguas, executavam suas táticas sensuais de atração dos marinheiros, dos comissários, 
negociantes ou de qualquer transeunte interessado e com condições financeiras suficientes a pagar por certos prazeres efêmeros da noite. Sabe-se que, desde a década de 1860, os portos brasileiros, sobretudo o do Rio de Janeiro e o de Santos, entraram na rota do tráfico internacional de mulheres judias para a prostituição, as 'escravas brancas', provenientes da Rússia, da Hungria, da Ucrânia, algumas com origem na França e em parte da Áustria, mas principalmente nas aldeias pobres de países do leste europeu (RAGO, 1991). O Cemitério Israelita de Cubatão, construído em Santos no ano de 1919 e transferido para Cubatão em 1930, guarda os restos mortais de 55 'polacas' que habitaram o solo santista na transição do século 19 para o século 20, permanecendo como um dos poucos vestígios que emolduram um conjunto de narrativas a ser desvendado, de morte e também de vida.

Convém notar que outros povos também afluíram a esse litoral e atuaram como atores sociais de importância inconteste no cultivo das marcas que passariam a compor o tecido populacional santista. Não obstante a inexistência de estudos acadêmicos sobre a presença árabe em Santos, alguns registros esparsos indicam, por exemplo, a crescente atuação de sírios (PAGEL, 2010) na comercialização ambulante de mercadorias e de pequenos objetos manufaturados, os mascates, e também no comércio local, tal como igualmente identificou Truzzi (1997) quanto às trajetórias laborais desses imigrantes pelo estado de São Paulo. Em comemoração ao $25^{\circ}$ aniversário da Sociedade Beneficente Síria, fundada em 1904, o jornal A Tribuna publicou uma reportagem na qual destacou o aumento da quantidade de sírios ${ }^{4}$ na cidade portuária, tendo como base os resultados de um recenseamento desenvolvido por essa mesma entidade no ano de 1905, no qual foram computados 406 imigrantes dessa nacionalidade, entre homens, mulheres e, inclusive, crianças (SOCIEDADE, 1929).

Naquele quadro de enriquecimento, modernização e multiculturalização de alguns territórios paulistas, o complexo cafeeiro, definitivamente, se consolidava no cenário comercial brasileiro e internacional: a exportação do

\footnotetext{
4 Também compreendem as populações originárias dos atuais territórios do Líbano, àquela época pertencentes à Grande Síria, sob o domínio Otomano.
} 
café, que registrou 36.250 sacas em 1860, alcançando 3.255.936 em 1892, chegou ao pico em 1909, com 13.453.104 de sacas do 'ouro verde' (GONÇALVES, 2006). E o porto de Santos continuou a receber grandes e muitas embarcações repletas de mercadorias e também de imigrantes, dinâmica que se estendeu pelas primeiras décadas do século 20.

\section{O 'novo' século: novos fluxos}

Em 1908, o navio Kasato Maru atracou no cais santista, trazendo o primeiro contingente de japoneses às fazendas de café e aos núcleos coloniais de São Paulo, computando 165 famílias, que totalizavam 781 imigrantes sob contrato, mais dez imigrantes espontâneos (HANDA, 1987; SAKURAI, 1999). Entre 1908 e 1914, registrou-se a entrada de oito navios japoneses no porto de Santos, transportando mais de 14 mil pessoas (OHNO, 2008).

Convém referir que o estreitamento das relações bilaterais entre o Brasil e o Japão, iniciado com o Tratado da Amizade, Comércio e Navegação, de 1895, culminou no convite por parte do governo brasileiro quanto ao envio de grupos de imigrantes japoneses dispostos a trabalhar no interior paulista, onde as plantações de café seguiam em ritmo e volume crescente, não obstante a instabilidade da mão de obra européia, que, com frequência, abandonava as lavouras ou migrava para outras fazendas onde as condições de trabalho, à primeira vista, pareciam menos hostis.

Sakurai (1999) e Ohno (2008) acentuam que também contribuiu para a atração de japoneses ao Brasil o fato de países como os Estados Unidos, Canadá e Austrália terem imposto inúmeras restrições burocráticas e medidas discriminatórias contra a chegada de imigrantes dessa nacionalidade. De outro lado, no Japão imperial da Restauração Meiji, as profundas transformações de ordem política e econômica desencadeadas pelo processo de industrialização e pela concomitante urbanização posicionaram o deslocamento migratório ao exterior como uma saída estratégica de sobrevivência àquela população, isto é, uma forma de compensar a rápida variação demográfica entre o campo e as 
cidades, com suas vastas consequências estruturais no seio familiar, e colmatar as necessidades sociais recrudescidas naquele panorama histórico de modernização.

A fixação territorial desses imigrantes no litoral santista ocorreu, principalmente, pela inadaptação nas fazendas cafeeiras para onde inicialmente se destinaram e onde se depararam com rotinas desgastantes de trabalho, com processos de estranhamento cultural e recorrente tratamento preconceituoso, uma vez que os 'amarelos' da Ásia não detinham valor simbólico compatível ao dos brancos europeus, os prediletos na ideológica hierarquia das alteridades legitimada política e economicamente no Brasil. Os primeiros imigrantes desertores da Fazenda do Canaã, circunvizinha à linha férrea da Mogiana, nas adjacências de Ribeirão Preto, chegaram a Santos ainda em 1908, em número de 31 pessoas (HANDA, 1987), todas provenientes da ilha de Okinawa, cuja capital, Naha, receberia, décadas mais tarde, o título de 'cidade-irmã' de São Vicente, município fisicamente conectado a Santos.

Handa (1987) menciona que, pouco a pouco, mais japoneses deixaram o interior e rumaram ao litoral, aglomerando-se no bairro ainda pouco habitado da Ponta da Praia, mas também nas zonas periféricas do Marapé, Saboó, Campo Grande, dedicando-se à pesca, à agricultura, ao artesanato, a ofícios como carpinteiros, tintureiros, quitandeiros, estivadores, operários, além de trabalhos nos bordéis e na Companhia Docas, onde os portugueses e espanhóis constituíam o coletivo de imigrantes majoritário. Alguns japoneses, nos processos de territorialização em Santos, também atuaram como pequenos comerciantes de produtos agrícolas e de pescado e como arrendatários de terras ociosas, que eram muitas, visto que a cidade, até então restrita às cercanias do centro comercial, começava a se esparramar por entre as artérias físicas que levariam à 'Barra'. Às mulheres, cabia a responsabilidade pela venda de peixes frescos no mercado ou de casa em casa, além dos rotineiros serviços domésticos, como arrumadeira, copeira ${ }^{5}$, faxineira, e na horticultura, que

\footnotetext{
${ }^{5} \mathrm{O}$ arquivo do jornal A Tribuna reúne uma quantidade de exemplares do período histórico aqui tratado, nos quais foram divulgados diversos anúncios de homens e mulheres japoneses à procura de trabalho, em particular para as funções de copeira e arrumadeira.
} 
formava uma verde superfície tão comumente identificada nos bairros onde se concentraram as famílias de japoneses, como a Ponta da Praia (RODRIGUES, 1980).

Mas não apenas esse bairro, antes do processo da generalizada urbanização da cidade, congregou as marcas concretas e imateriais da presença de imigrantes japoneses. Da região do pantanoso Saboó ao agitado e ruidoso Valongo, as chácaras de frutas, legumes e verduras, as criações de porco, os pequenos chalés de madeira, o vaivém de mulheres e homens japoneses que reproduziam seu capital financeiro e suas territorialidades, também, pelas interações sociais extracomunitárias, eram diversos os elementos que sinalizavam a composição étnica daquele que ficara conhecido como o Bairro Chinês: "por terem olhos rasgados, foram confundidos com chineses, daí o aparecimento do nome popular" (MONDIN, 1983).

A propósito, durante a ditadura militar no Brasil, mais precisamente na década de 1970, o Bairro Chinês, após anos de existência e de protagonismo na cena social e comercial santista, foi extinto do mapa geográfico de Santos e anexado a um dos bairros adjacentes, o Valongo, como parte do replanejamento urbano. Entrementes, tamanha fora a simbologia que esse território assumiu na memória social santista que, em 19 de julho de 2011, após reinvindicação dos seus moradores e posterior representação pública por parte da Câmara Municipal, o Bairro Chinês foi oficializado na nova planta topográfica dos bairros de Santos, estendendo-se dos sopés dos morros da Penha, Pacheco e São Bento até a Avenida Getúlio Vargas, entre o centro e o bairro do Saboó (Mapa 3). Em definitivo, trata-se de "rastros do passado em meio à cidade do presente, fragmentos de uma temporalidade escoada detentores de história acumulada (PESAVENTO, 2007: s/p.). 
Mapa 3 -Mapa dos bairros de Santos

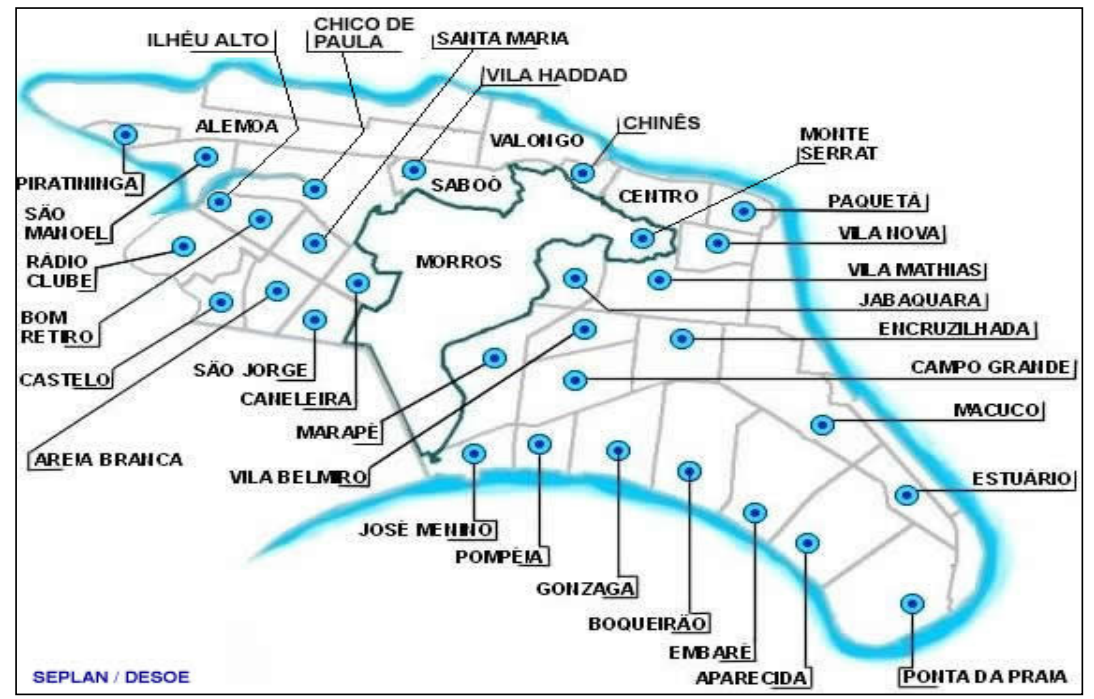

Fonte: Página virtual Invest Santos - Seção Bairro a Bairro, 2014.

Importante resgatar, neste panorama demográfico, os dados referentes à população de Santos em 1913, que contabilizava trinta milhares de pessoas a mais do que se registrou na década anterior, especificamente em 1900. Naquele ano que antecedia a eclosão da Primeira Guerra Mundial e, não por coincidência, os deslocamentos populacionais ao Brasil alcançaram elevados índices (BASSANEZI, 1996; BAENINGER, 2012), o censo municipal registrou 22.787 portugueses, 8.291 espanhóis, 3.164 italianos, 880 turcos (respeitando-se a condição geopolítica do Império Turco-Otomano, sem distinção quanto a sírio-libaneses, antioquinos ${ }^{6}$ ou outras etnias e nacionalidades), 651 japoneses $^{7}$, que representavam, juntos, pouco menos da metade da população da cidade, de 88.967 habitantes (SANTOS, 1914).

Indivíduos de outras nacionalidades, embora em menor número, foram também computados pelo censo municipal daquele ano, o que evidencia o

\footnotetext{
${ }^{6}$ Os antioquinos radicaram-se em Santos assim que teve início a Primeira Guerra, tendo fundado, no dia 11 de outubro de 1925, na Rua General Câmara, 125, região central da cidade, a Sociedade União Antioquina de Santos, atualmente em funcionamento, com sede na Rua Mato Grosso, n. 404, no bairro do Boqueirão. Na obra Poliantéia Santista, Lichti (1996) faz menção à presença de mais de 60 antioquinos na assembleia de fundação dessa entidade.

${ }^{7}$ A reportagem publicada na primeira página do jornal A Tribuna, de 22 de março de 1914, faz menção à presença de mais de mil japoneses residindo em Santos, "[...] em sua maioria homens válidos, rapagões robustos, sóbrios e de uma resistência para os mais árduos trabalhos” (A INVASÃO, 1914).
} 
caráter multicultural da configuração populacional do município santista, tal como aponta a Tabela 3, a seguir.

Tabela 3 - Distribuição de estrangeiros em Santos por nacionalidade, 1913

\begin{tabular}{lr}
\hline Nacionalidade & N \\
\hline Portugal & 22.787 \\
\hline Espanha & 8.291 \\
\hline Itália & 3.164 \\
\hline Turquia & 880 \\
\hline Japão & 651 \\
\hline Alemanha & 478 \\
\hline Inglaterra (Escócia e Irlanda) & 309 \\
\hline Áustria-Hungria & 226 \\
\hline França & 218 \\
\hline Rússia & 172 \\
\hline Argentina & 124 \\
\hline Estados Unidos da América & 80 \\
\hline Holanda & 70 \\
\hline Suíça & 57 \\
\hline Bélgica & 36 \\
\hline Uruguai & 31 \\
\hline Chile & 10 \\
\hline Paraguai & 10 \\
\hline Europeus em geral & 166 \\
\hline Asiáticos em geral & 29 \\
\hline Americanos em geral & 20 \\
\hline Africanos em geral & $\mathbf{3 7 . 8 3 8}$ \\
\hline Nacionalidade ignorada & \\
\hline Total &
\end{tabular}

Fonte: Recenseamento da Cidade e Município de Santos, 31/12/1913. Prefeitura Municipal de Santos, 1914.

A eclosão da Primeira Guerra Mundial, como já dito, provocou a intensificação dos deslocamentos populacionais à América, numa dimensão tamanha que, ao término do conflito, Santos ultrapassava 100 mil moradores no seu território, computando 102.589 em 1920, segundo recenseamento do governo federal (FIBGE, 1920). Apenas para efeitos de elucidação numérica, precisamente no que diz respeito à imigração síria em Santos (na Tabela 3 concebida como população turca), que não fora das mais expressivas em termos quantitativos, sua população passou de cerca de 400 indivíduos no dealbar da primeira década do século para um contingente próximo a dois mil, ao fim do 
segundo decênio (SOCIEDADE, 1929), representando um aumento de aproximadamente $500 \%$.

Não coincidentemente, a partir da segunda década do século 20, fundaram-se muitas escolas, igrejas e templos frequentados por imigrantes na cidade litorânea do café, que seguia com sua metamorfose urbana e territorial. Os fluxos de migrações internacionais alocadas em Santos só diminuíram significativamente em meados de 1930, quando o governo de Getúlio Vargas instituiu pesadas restrições nacionalistas quanto à entrada de imigrantes no país, culminando na aprovação da emenda constitucional que ficou conhecida como a 'Lei de Cotas', pela qual se estabeleceu que o limite anual para a recepção de novos imigrantes, para cada nacionalidade, excetuando-se a portuguesa, não excederia $2 \%$ da quantidade total dos respectivos membros já fixados no Brasil nas cinco décadas precedentes (HOLLOWAY, 1984).

Santos, que vira todo o seu processo de modernização sistematicamente assegurado pelo complexo cafeeiro integrado (CANO, 2007), deparou-se com o estado de notória pauperização e comprometimento das relações econômicosociais e de suas paisagens urbanas (ANDRADE, 1989). As migrações internacionais, que operaram de forma visceral na configuração da estrutura espacial e do tecido sociocultural dessa importante cidade paulista, diminuíram e abriram espaço, a partir de 1940 e com maior volume nos anos 1950, para o movimento de migrações internas oriundas do Nordeste brasileiro, no compasso da penetração e expansão do capitalismo e da incipiente industrialização desencadeada nos maiores centros urbanos da Região Sudeste.

\section{Considerações finais}

A constituição do território santista de migrações internacionais teve seu primeiro vulto na transição do século 19 para o século 20, na esteira das dinâmicas políticas, econômicas e populacionais orientadas pelo mercado cafeeiro em expansão no estado de São Paulo, nos quadros da República nascente. Efetivamente, Santos atuou como um dos nódulos da economia 
focada na monocultura latifundiária do café, que dependeu do porto desta cidade para o escoamento dos grãos e para a recepção, por mar, de levas de imigrantes para trabalhar em todo o eixo de produção e comercialização do 'ouro verde', do interior ao litoral paulista.

As conjunturas históricas neste estudo apresentadas são de importância fundamental para o entendimento das configurações populacionais que fariam de Santos, nas derradeiras décadas oitocentistas, uma urbe com traços modernos e multiculturais. A passagem do século 19 para o século 20, em particular, deve ser examinada como o marco temporal no bojo do qual esta cidade portuária consolidou-se como território de migrações internacionais na geografia paulista. A regularidade dos fluxos migratórios, amparados por políticas de subvenção e pela ideologia segregacionista do branqueamento populacional, fez com que a população santista, que em 1872 contabilizava pouco mais de nove mil habitantes, ultrapassasse 50 mil moradores em 1900, quase a metade constituída por estrangeiros, de acordo com as fontes oficiais apresentadas neste estudo. Destaque particular deve ser conferido aos portugueses, que em 1872 já somavam aproximadamente mil pessoas, segundo o censo municipal.

Quantitativamente, Santos crescia em termos populacionais, e à cidade acresciam-se, qualitativamente, transformações estruturais que abarcavam as esferas do trabalho, da cultura, da moralidade, dos hábitos de vida, etc. Portugueses, alemães, franceses, ingleses, espanhóis, italianos, 'polacas', japoneses, sírios, entre outros sujeitos de nacionalidades distintas, ainda por serem desvendadas pelos investigadores, inscreveram suas marcas nesse território de multiculturalidade. Da expansão do 'porto do café' à introdução de novas concepções sobre o urbano, os imigrantes atuaram, pois, como agentes propulsores da transição de uma cidade provinciana e até então acanhada para a urbe que se pretendia com 'ares' progressistas. As associações organizadas por portugueses, espanhóis, italianos, ingleses, entre tantos outros, exerceram papel decisivo nesse processo histórico de transformação territorial e social, dos oitocentos aos novecentos. Inclusive a configuração de bairros, como os morros que margeiam a cidade e ainda entoam modos de vida reproduzidos por 
imigrantes portugueses e seus descendentes ou mesmo a extensão física oficialmente reconhecida como Bairro Chinês, em referência aos japoneses que o habitaram, corresponde à importante atuação dos imigrantes na formação do município santista.

No alvorecer dos novecentos, a cidade portuária dos volumosos fluxos econômicos posicionava-se, assim, como a cidade alinhavada por múltiplos fragmentos de cultura que lhe davam corpo. Tanto que, em 1913, quase 89 mil indivíduos residiam nesse município, praticamente a metade deles composta por imigrantes pertencentes a mais de 20 nacionalidades, como demonstrado neste estudo. Suas trajetórias de vida foram decisivas para a composição das linhas fundantes que hoje caracterizam esta urbe, particularmente no tocante às formas de organização e trabalho, à estrutura comercial, à organização associativista e política, à formação territorial, às festividades, linguajares, à produção material e imaterial de culturas, enfim. Compreender a formação e a transformação desse município requer, pois, a investigação acurada das diferentes populações que o habitaram, que lhe ofertaram forma e conteúdo.

\section{Referências}

A INVASÃO amarela no Campo Grande. A Tribuna, anno XX, Santos, 22 de março de $1914 . \quad$ Disponível em: http://www.novomilenio.inf.br/santos/h0388a.htm. Acesso em: 26 fev. 2016.

ÁLVARO, Guilherme. A campanha sanitária de Santos: suas causas e seus effeitos. São Paulo: Casa Duprat, 1919.

ANDRADE, Wilma T. F. de. O discurso do progresso: a evolução urbana de Santos (1870-1930). 1989. 265f. Tese (Doutorado em História) Faculdade de Filosofia, Letras e Ciências Humanas, Universidade de São Paulo, São Paulo, 1989.

BAENINGER, Rosana. Fases e faces da migração em São Paulo.Campinas: Núcleo de Estudos da População - Nepo/Unicamp, 2012.

BASSANEZI, Maria S. C. B. Imigrações internacionais no Brasil: um panorama histórico. In: PATARRA, Neide L. (coord.). Emigração e imigração internacionais no Brasil contemporâneo. Campinas: FNUAP, 1996. (org.). São Paulo do passado: dados demográficos 1854. V. II.

Campinas: Núcleo de Estudos de População/Universidade Estadual de 
Campinas,

1998.

Disponível

em:

http://www.nepo.unicamp.br/publicacoes/censos.html. Acesso em: 27 maio 2015.

BLUME, Luís Henrique dos S. O Porto Maldito: modernização, epidemias e moradia da população pobre em Santos no final do século XIX. In: FENELON, Déa Ribeiro (org.). Cidades. vol. 1. $1^{\text {a }}$ ed. São Paulo: Olho D'Água, 1999. p. 129-151.

CAMARGO, Haroldo L. Santos, Alemães e o Cemitério Protestante: Colônias estrangeiras e Patrimônio cultural. Revista Eletrônica Patrimônio: Lazer \& Turismo, Universidade Católica de Santos, Santos, out. 2006, não paginado. Disponível em: $<$ http://www.unisantos.br/pos/revistapatrimonio/artigos.php?cod=83 $>$. Acesso em: 16 de mar. 2012.

CANO, Wilson. Raízes da Concentração Industrial em São Paulo. $5^{\mathrm{a}}$. ed. V. 1. Campinas: IE-Unicamp, 2007.

CÁNOVAS, Marília D. K. Espanhóis na Santos da bèlle époque: o espaço expressão da contradição. Resultados preliminares de uma pesquisa. Maracanãa, Programa de Pós-graduação em História, IFCH/UERJ, v. VI, n. 6, jan/dez. 2010, p. 97-122.

CARVALHO, Beth C. de. Os imigrantes. A Tribuna, 12 de junho 1982. Disponível em: <http://www.novomilenio.inf.br/santos/h0150.htm>. Acesso em: 04 mar. 2016.

FAUSTO, Boris (org.). História geral da civilização brasileira. Tomo III. Brasil República. São Paulo: Difel, 1977.

. Fazer a América:a imigração em massa para a América Latina. São Paulo: Edusp, 1999.

FIBGE. FUNDAÇÃO INSTITUTO BRASILEIRO DE GEOGRAFIA E ESTATÍSTICA. Synopse do recenseamento de 31 de dezembro de 1872. Rio de Janeiro: Officina da Estatistica, 1872.

Synopse do recenseamento de 31 de dezembro de 1900. Rio de Janeiro:

Officina da Estatistica, 1900. Disponível em: http://www2.senado.leg.br/bdsf/handle/id/4/browse?value=Censo+demogr\%C3 \%A1fico\%2C+Brasil\%2C $+1900 \&$ type=subject. Acesso em: 10 out. 2012. . Recenseamento Geral do Brasil.Série Nacional. 1920. IBGE, Brasil.

FIRVEDA, Jurema N. Società Italiana di Santos: 1897-1990. Monografia (PósGraduação Lato Sensu em História) - Universidade Católica de Santos, Santos, 1990. 
FRUTUOSO, Maria S. G. Imigração portuguesa e sua influência no Brasil: o caso de Santos -1850 a 1950. 162f. Dissertação (Mestrado em História) Faculdade de Filosofia, Letras e Ciências Humanas, Universidade de São Paulo, São Paulo, 1990.

. A presença portuguesa no comércio de Santos. In: MATOS, Maria Izilda; SOUSA, Fernando de; HECKER, Alexandre (Org). Deslocamentos \& Histórias: Os Portugueses. Bauru: EDUSC, 2008.

GONÇALVES, Alcindo. Desenvolvimento econômico da Baixada Santista.Santos: Leopoldianum, 2006.

HANDA, Tomoo. Imigrante japonês: História de sua vida no Brasil. São Paulo: T A Queiroz, 1987. (Coleção Coroa Vermelha Estudos Brasileiros).

HOBSBAWM, Eric. A era do capital:1848-1875. Rio de Janeiro: Paz e Terra, 2009.

HOLLOWAY, Thomas. Imigrantes para o café: café e sociedade em São Paulo, 1886-1934. Rio de Janeiro: Paz e Terra, 1984.

KIDDER, Daniel P. Reminiscências de viagens e permanência no Brasil. São Paulo: EDUSP, 1972.

LAMBERG, Maurício. O Brazil. Illustrado com Gravuras. Rio de Janeiro: Lombaerts/Typographia Nunes, 1896.

LANNA, Ana L. D. Uma cidade na transição: Santos, 1870/1913. São Paulo: HUCITEC, 1996.

LASCANE, José. Blog, 2015. Disponível em: http://www.lascane.com.br/homenagem.html. Acesso em: 10 jan. 2015.

LEITE, Joaquim da Costa. O transporte de emigrantes: da vela ao vapor na rota do Brasil, 1851-1914. Análise Social, vol. XXVI (112-113), 1991, p. 741-752. Informação ou Propaganda? Parentes, Amigos e Engajadores na Emigração Oitocentista. Emigração/Imigração em Portugal. Actas do Colóquio Internacional Sobre Emigração e Imigração em Portugal - Séculos XIX e XX. Lisboa: Ed. Fragmentos, 1993, p. 98-107.

LICHTI, Fernando M. Polianteia santista. Vol. 3. São Vicente: Editora Caudex, 1996.

LISBOA, Wellington T. Santos, em duas viradas de século (do século 19 ao século 20 e do século 20 ao século 21): dinâmicas de configuração social do território de migrações internacionais. 283f. Tese (Doutorado em Sociologia) Instituto de Filosofia e Ciências Humanas, Universidade Estadual de Campinas, Campinas, 2015. 
A comunicação como elemento articulador na construção dos territórios e das identidades: o caso das associações de imigrantes em Santos/SP. Anais do $40^{\circ}$ Congresso Brasileiro de Ciências da Comunicação, Intercom, Curitiba, $2017 . \quad$ Disponível em: http://portalintercom.org.br/anais/nacional2017/resumos/R12-3013-1.pdf.

Acesso em: 10 maio 2018.

MARTINEZ, Elda E. G. O Brasil como país de destino para os imigrantes espanhóis. In: FAUSTO, Boris (org.). Fazer a América. São Paulo: EDUSP, 1999. p. 239-271.

MATOS, Maria I. S. de. História, memória e cotidiano privado. O feminino e o masculino no porto do café (1890-1930). In: PEREIRA, Maria Ap. F. (org.). Santos- Café \& História. Santos: Leopoldianum, 1995.

MONDIN, Leda. Prosperidade e decadência, as duas faces do Valongo. 1983. Disponível em: http://www.novomilenio.inf.br/santos/h0100b32.htm. Acesso em: 04 fev. 2014.

MULLER, Daniel P. Ensaio d'um quadro estatístico da provincia de S. Paulo: ordenado pelas leis provinciaes de 11 de abril de 1836 e 10 de março de 1837. Reedição litteral. São Paulo: secção de obras d' "O Estado de S. Paulo, 1923.

OHNO, Masao. Centenário da imigração japonesa no Brasil. São Paulo: Larousse, 2008.

PAGEL, Geovana. A forte presença árabe em Santos.In: AGÊNCIA DE NOTÍCIAS ÁRABE-BRASIL, 2010. Disponível em: http://www.anba.com.br/noticia_servicos.kmf?cod=11180838. Acesso em: 08 fev. 2015.

PEREIRA, Maria Ap. F. O Comissário do Café no Porto de Santos (18701920). Dissertação. (Mestrado em História Econômica) - Faculdade de Filosofia, Letras e Ciências Humanas, Universidade de São Paulo, 1980.

. Portugueses no alto comércio santista no início da República Velha. In: MATOS, Maria I.; SOUSA, Fernando de; HECKER, Alexandre (Org). Deslocamentos \& Histórias: Os Portugueses. Bauru: EDUSC, 2008.

PESAVENTO, Sandra. Cidades Visíveis, Cidades Possíveis, Cidades Imaginadas. Revista Brasileira de História, v. 27, São Paulo, 2007. Disponível em:http://www.scielo.br/scielo.php?pid=S0102-

01882007000100002\&script=sci_arttext Acesso em: 07 jul. 2015.

PETRONE, Maria T. S. Imigração. In: FAUSTO, Boris (org.). História Geral da Civilização Brasileira. O Brasil Republicano. Sociedade e Instituições (1889-1930). Tomo III. Vol. 2. 4ª edição. Rio de Janeiro: Bertrand Brasil, 1999. 
PORTA, Eliane V. Imigrantes espanhóis em Santos, 1880-1920. 211f. Tese (Doutorado em História Econômica) - Faculdade de Filosofia, Letras e Ciências Humanas, Universidade de São Paulo, São Paulo, 2007.

PRADO JÚNIOR, Caio. A cidade de São Paulo: geografia e história. São Paulo: Brasiliense, 1989.

RAGO, Margareth. Os prazeres da noite: prostituição e códigos de sexualidade feminina em São Paulo. $1^{a}$ ed. São Paulo: Ed. Paz e Terra, 1991.

RAMOS, Márcia C. de S. A imigração italiana em Santos: 1888-1940. Monografia (Pós-graduação Lato Sensu em História) - Universidade Católica de Santos, Santos, 1990.

RODRIGUES, Olao. Cartilha da História de Santos.Santos: Gráfica da Prodesan, 1980.

SAKURAI, Celia. Imigração japonesa para o Brasil: um exemplo de imigração tutelada. In: FAUSTO, Boris. Fazer a América: a imigração em massa para a América Latina. São Paulo: EDUSP, 1999.

SANTOS, Francisco M. dos; LICHTI, Fernando M. História de Santos: Poliantéia Santista. $2^{a}$ ed. São Vicente: Caudex, 1986.

SANTOS. Prefeitura Municipal. Recenseamento da cidade e município de Santos em 31 de Dezembro de 1913. 1914. Disponível em: $<$ http://www.novomilenio.inf.br/santos/h0296a01.htm>. Acesso em: 20 set. 2014.

SERRANO, Fábio. Aspectos da arquitetura de Santos no ciclo do café. In: PEREIRA, Maria Ap. F. (org.). Santos - Café \& História. Santos: Leopoldianum, 1995. p. 107-119.

SOCIEDADE Beneficente Síria. A Tribuna, 1929. Disponível em: http://www.novomilenio.inf.br/santos/h0260u.htm. Acesso em: 10 fev. 2015.

TRUZZI, Oswaldo M. S. Patrícios: sírios e libaneses em São Paulo. São Paulo: Hucitec, 1997.

Recebido em: 1 de junho de 2020 Aceito em:5 de outubro de 2020 